\title{
Outcomes of Layered versus Mass Closure in Transverse Incision during Emergency Laparotomy in Children
}

\author{
Khandoker Moynul Hasan 1*, Shahnoor Islam1, Md. Ashraf Ul Huq1, Muhammed Moinul Huque², \\ Shah Md. Rezaul Karim ${ }^{3}$, Mohammad Shafiul Azam', Md. Iqbal Hossain Talukder5, \\ Sharmin Ara Begum6, Mohammad Kamrul Ahsan', A. K. M. Shahidur Rahman ${ }^{8}$ \\ ${ }^{1}$ Department of Pediatric Surgery, Dhaka Medical College Hospital (DMCH), Dhaka, Bangladesh \\ ${ }^{2}$ Department of Pediatric Urology, Dhaka Medical College Hospital (DMCH), Dhaka, Bangladesh \\ ${ }^{3}$ Department of Surgery, Sheikh Hasina Medical College Hospital, Habiganj, Bangladesh \\ ${ }^{4}$ Department of Urology, National Institute of Kidney Diseases and Urology (NIKDU), Dhaka, Bangladesh \\ ${ }^{5}$ Department of Surgery, Sheikh Hasina Medical College Hospital, Tangail, Bangladesh \\ ${ }^{6}$ Department of Anesthesiology, National Institute of Traumatology and Orthopedic Rehabilitation (NITOR), Dhaka, Bangladesh \\ ${ }^{7}$ Holy Family Red Crescent Medical College Hospital (HFRCMCH), Dhaka, Bangladesh \\ ${ }^{8}$ Department of Nephrology, Bangabandhu Sheikh Mujib Medical University (BSMMU), Dhaka, Bangladesh \\ Email: ^hasan.khandoker@yahoo.com
}

How to cite this paper: Hasan, K.M., Islam, S., Ul Huq, Md.A., Huque, M.M., Karim, S.Md.R., Azam, M.S., Talukder, Md.I.H., Begum, S.A., Ahsan, M.K. and Rahman, A.K.M.S. (2020) Outcomes of Layered versus Mass Closure in Transverse Incision during Emergency Laparotomy in Children. Journal of Biosciences and Medicines, 8, 180-193. https://doi.org/10.4236/jbm.2020.88016

Received: July 23, 2020

Accepted: August 22, 2020

Published: August 25, 2020

Copyright (c) 2020 by author(s) and Scientific Research Publishing Inc. This work is licensed under the Creative Commons Attribution International License (CC BY 4.0).

http://creativecommons.org/licenses/by/4.0/ (c) (i) Open Access

\begin{abstract}
Background: The value of laparotomy closure technique may be measured by the incidence of early and late wound complications. The best laparotomy closure technique should be less time consuming, easy and cost-effective, while preventing both early and late complications. Objective: To compare the outcomes of layered versus mass closure in transverse incision during emergency laparotomy in children. Methods: This prospective comparative study was conducted at Department of Pediatric Surgery, Dhaka Medical College Hospital (DMCH), Dhaka, Bangladesh from July 2016 to June 2018. A total of 60 pediatric age cases that underwent laparotomy were included in this study. Cases were randomly allocated into two groups; 30 patients were in Group A (Layered closure) and 30 patients were in Group B (Mass closure). The outcome variables were time required for wound closure, wound infection, wound dehiscence and incisional hernia. Data were analyzed and compared by statistical tests. Results: The mean age of Group A and Group B patients were $31.08 \pm 30.25$ months and $34.70 \pm 42.73$ months respectively (p $=0.706$ ). The ratio between male and female subject was 1.1:1 in Group A and 3.3:1 in Group B. The common diseases of the study patients who underwent laparotomy were intussusceptions, intestinal obstruction due to bands and adhesion, perforated appendix and perforation of small intestine
\end{abstract}


due to blunt trauma respectively. Mean wound closure time was significantly less in mass closure group [28.20 \pm 2.17 minutes in layered closure group and $18.80 \pm 1.67$ minutes in mass closure group, $(\mathrm{p} \leq 0.001)]$. Wound infection rate, incidence of superficial wound dehiscence, and incisional hernia were relatively less in mass closure group, however, the differences were not statistically significant $(\mathrm{p}=0.053, \mathrm{p}=0.095$ and $\mathrm{p}=0.301$ respectively). There was no complete wound dehiscence in Group A, but that was in $1(3.3 \%)$ patient in Group B ( $p=0.313)$. Conclusion: Mass closure technique is comparatively better than layered closure technique.

\section{Keywords}

Laparotomy, Layered Closure, Mass Closure

\section{Introduction}

Laparotomy is a surgical procedure refers to a large incision through the abdominal wall that involves all layers to gain access into the abdominal cavity. It is a major surgical procedure, whether elective or emergency [1]. Emergency laparotomy is one that must be performed without any delay; the patient has no choice other than immediate laparotomy; if they do not want to do so, there is a risk of permanent disability or death. The choice of surgical incision to open the abdominal cavity should be based on patient's condition, expertise of surgeon, or health care system criteria [2]. From patient's point of view-condition of the patient, severity of pain and restriction of ingestion are important [2]. Surgeons' main interests, aside from the elective or emergency exposure of the operative field are time required to open and close the abdomen, frequency of burst abdomen, incidence of wound infection, postoperative pulmonary complications and incisional hernias [2]. Regarding health care system-health economy, parameters such as duration of operation, length of hospital stay and full physical and mental activity are relevant [3]. The abdomen of a neonate, infant or young child is little bit more square than rectangular. Accordingly, the transverse incision affords optimal access to all areas of the abdominal cavity. The incision is usually closed in layers. Mass closure is also an option [4].

Layered closure is the technique which reconstructs the anterior and posterior aponeurotic sheaths separately with the posterior layer generally incorporating the peritoneum [5]. The primary advantage of this closure is that multiple suture strands exists, so that if a suture breaks, the incision is held intact by the remaining sutures [5] [6].

Mass closure involves a single-layer closure of all layers and may or may not include the peritoneum [5]. This method allows even distribution of tension across the entire length of the suture that results in minimization of tissue strangulation. The goal is approximation of tissue edges to allow scar formation. Excessive tension leads to tissue necrosis and eventual failure of the closure [6] [7]. 
Post-operative wound complications may be both early and late complications. Early complications include wound dehiscence and wound infection, while late complications are incisional hernia and incisional pain [2]. Abdominal wound dehiscence is a severe complication of abdominal surgery in children [8]. It was reported that, in children incidence of abdominal wound dehiscence after laparotomy was $0.2 \%-1.2 \%$ with associated mortality rates were $8 \%-45 \%$ [8]. Wound infection is defined as the presence of seropurulent discharge (pus) through the sutured wound or erythema/induration around the suture line for more than $2 \mathrm{~cm}$ on either side [9]. In children, surgical site infection is higher due to inadequate body defense mechanisms. The presences of peritonitis, contamination by bowel contents are some of the common factors which increase the wound infection rates [10]. Besides, the choice of suture material and suture technique also has an important role in post-operative wound infection. It has been reported that the rate of post-operative wound infection in mass closure technique was less as compared to the layered closure technique [2] [10].

Incisional hernia is the consequence of concealed wound dehiscence that may occur months or years after laparotomy, which is closely related to the suture technique. It was documented that the incidence of incisional hernia was less in mass closure technique [10].

Despite advances in surgical techniques and materials, abdominal fascial closure has remained a procedure that often reflects a surgeon's personal preference with a reliance on tradition and their experience [11]. There were many studies regarding laparotomy wound closure techniques in adults around the world but very few studies were conducted in children [2] [4] [5]. In Bangladesh there is scarce evidence regarding this issue. Therefore this study was designed to observe the outcomes of layered versus mass closure in transverse incision during emergency laparotomy in children.

\section{Materials and Methods}

This prospective comparative study was conducted among the children underwent emergency laparotomy by transverse incision in Department of Pediatric Surgery, Dhaka Medical College and Hospital (DMCH), Dhaka, Bangladesh during the period of July 2016 to June 2018. A total of 60 patients were selected as cases by statistical calculation [using, $n=Z^{2}(p \times q) / d^{2}$ equation] and randomly allocated to two groups. Group A consisted of 30 patients who underwent layered closure and Group B consisted of 30 patients who underwent mass closure. All the odd-numbered cases were allocated for group A and the even-numbered cases were allocated for group B. This study was approved by the Ethical Review Committee, Dhaka Medical College, Dhaka, Bangladesh. The study subjects were enrolled according to the selection criteria. Inclusion criteria were; children under 12 years of age required emergency laparotomy by transverse incision for intestinal obstruction, intussusceptions, perforation of gas containing hollow viscus and blunt/penetrating trauma in abdomen. On the other hand; patients having laparoscopic procedures in any emergency cases, all 
other abdominal incision except transverse incision, transverse incision with stoma, and patients having previous laparotomy were excluded from the study. Written informed consent was taken from the parents or legal guardians for every case. Each study subject was evaluated by history, physical examination and investigation. History was taken regarding nature and duration of the problem along with any congenital anomaly. Information regarding age, gender and provisional diagnosis was recorded accordingly. Physical examination included general examination and examination of the abdomen. All patients were investigated properly by urine for routine microscopic examination (Urine- $\mathrm{R} / \mathrm{M} / \mathrm{E}$ ), complete blood count (CBC), serum creatinine, chest $x$-ray, plain $x$-ray abdomen and ultrasonography of whole abdomen (in selected cases). Other investigations were done as needed. Standard operative procedure was followed in every case. The differences within outcome variables between the groups were analyzed and compared; these were time (minute) required for wound closure, post-operative wound infection rate, incidence of wound dehiscence and incisional hernia.

\subsection{Pre-Operative Prophylactic Antibiotic Management}

In both group, prophylactic antibiotic was given pre-operatively by following way-

- Just before induction neonate was given Inj. Ceftazidime at $100 \mathrm{mg} / \mathrm{kg}$, while infant and children were given Inj. Ceftriaxone at $100 \mathrm{mg} / \mathrm{kg}$ [12].

- If operation last more than $3-4$ hours in neonate a $2^{\text {nd }}$ dose of Inj. Ceftazidime at $100 \mathrm{mg} / \mathrm{kg}$ was given [13].

\subsection{Per-Operative Tools and Evaluation}

Suture material: Polyglactin 910 (Vicryl)

- Neonate, infant and children less than 5 years: $4 / 0 \& 3 / 0$ gauge

- Children more than 5 years: $2 / 0$ gauge

Suture technique: Continuous Operation technique

- Prepared the skin at the surgical site immediately before incision using an antiseptic (aqueous or alcohol-based) preparation: povidone iodine or chlorhexidine.

- Layered closure: At first peritoneum was closed by continuous suture, then posterior fascial layer and then anterior fascial layer by continuous suture.

- Mass closure: Peritoneum, posterior and anterior fascial layer was closed by single continuous suture.

- Timing of wound closure was recorded from the beginning of closure to the ending of closure in minutes by stop watch.

- Covered the surgical incisions with an appropriate interactive dressing at the end of the operation.

\subsection{Postoperative Evaluation of the Outcome Variables}

Wound infection: Post-operative wound infection or Surgical Site Infection 
(SSI) was evaluated by ASEPSIS Wound Score [14] on $5^{\text {th }}$ and $10^{\text {th }}$ post-operative day (POD). Check dressing was done at $5^{\text {th }}$ POD. Points were given for the need for Additional treatment, the presence of Serous discharge/exudates, Erythema, Purulent exudate, and Separation of the deep tissues, the Isolation of bacteria, and the duration of inpatient Stay (ASEPSIS) [14].

\section{ASEPSIS wound score}

\begin{tabular}{clccccc}
\hline & \multicolumn{5}{c}{ Proportion of wound affected } \\
\hline Wound characteristic & 0 & $<20$ & $20-39$ & $40-59$ & $60-79$ & $>80$ \\
\hline Serous exudate & 0 & 1 & 2 & 3 & 3 & 5 \\
Erythema & 0 & 1 & 2 & 3 & 3 & 5 \\
Purulent exudate & 0 & 2 & 3 & 6 & 8 & 10 \\
Separation of deep tissues & 0 & 2 & 3 & 6 & 8 & 10
\end{tabular}

Points are scored for daily wound inspection

\begin{tabular}{cc}
\hline Criterion & Points \\
\hline Additional treatment: & 10 \\
Antibiotics & 5 \\
Drainage of pus under local Anaesthesia & 10 \\
Debridement of wound (general anaesthesia) & daily 0 - 5 \\
Serous discharge* & daily 0 - 5 \\
Erythema & daily 0 - 10 \\
Purulent exudates & daily 0 - 10 \\
Seperation of deep tissues & 10 \\
Isolation of bacteria & 5 \\
Stay as inpatient prolonged over 14 days &
\end{tabular}

${ }^{*}$ Given score only on five of seven days. Highest weekly score used.

\section{Category of infection: total score $\mathbf{0}-10=$ satisfactory healing;}

$11-20=$ disturbance of healing; $20-30=$ minor wound infection;

$31-40=$ moderate wound infection; $>40=$ severe wound infection.

ASEPSIS wound scoring was done at the time of dressing on $5^{\text {th }}$ and $10^{\text {th }}$ POD. In case of wound infection daily dressing and scoring was done. Patients with post-operative surgical site infection had purulent discharge (pus) from the wound. In case of purulent discharge, discontinuation of antibiotic for 72 hours and then pus was sent for culture sensitivity test and then start to use appropriate antibiotic according to the sensitivity report.

Wound of all patients were checked after operation at $5^{\text {th }}$ and $10^{\text {th }}$ POD for superficial and complete wound dehiscence.

Superficial wound dehiscence: It refers to gaping of skin and subcutaneous 
tissue after removal of stitches 2 weeks postoperatively. The symptoms of wound dehiscence include visibly broken sutures before the wound has healed completely, along with renewed pain, bleeding and drainage from the surgical wound site [15].

Complete wound dehiscence: Complete wound dehiscence, present as all layers being separated with underlying tissue and organs being exposed and sometimes protruding through the wound opening. It occurs either gradually with a "tell-tale" serosanguineous discharge or suddenly with protrusion of a knuckle of bowel or omentum through the wound [15].

Incisional hernia: Incisional hernia is the consequence of concealed wound dehiscence allowing abdominal tissues and/or organs to push through the abdominal wall that may occur months or years after laparotomy [15].

\subsection{Follow up Visits}

After discharge from the hospital, all study patients were followed up at $30^{\text {th }}$ post-operative day (POD) and $90^{\text {th }}$ POD for incisional hernia.

\subsection{Statistical Analysis}

Statistical analysis was performed using the Statistical Package for Social Science (SPSS) software version 21.0. Categorical data were presented as frequency/percentage and continuous variable was expressed as mean $\pm \mathrm{SD}$ (standard deviation). The statistics used to analyze the data were descriptive statistics and the tests done were Student's " $t$ " test and Chi-square test. The level of significance was set at 0.05 and $p$ value $<0.05$ was considered significant.

\section{Results}

This study was intended to compare the outcomes of layered versus mass closure in transverse incision during emergency laparotomy in children. A total 60 (sixty) patients were randomly allocated to Group A (consisted 30 patients who underwent layered closure) and Group B (consisted 30 patients who underwent mass closure).

Table 1 shows the age distribution of the study subjects between two groups. The mean age of Group A and Group B were $31.08 \pm 30.25$ months and $34.70 \pm$ 42.73 months respectively. Age range of study subjects in Group A was 0.06 months to 96 months and that was 0.13 months to 144 months in Group B. Mean age difference was not statistically significant between the groups ( $p=$ 0.706).

Table 2 shows gender distribution of study subjects between two groups. In Group A, 16 (53.3\%) study subjects were male and 14 (46.7\%) were female. On the other hand, in Group-B, 23 (76.7\%) subjects were male and 7 (23.3\%) were female. The ratio between male and female subject was 1.1:1 in Group A and 3.3:1 in Group B respectively.

Regarding the diseases of the study patients who underwent laparotomy, the 
Table 1. Distribution of age between two groups $(\mathrm{N}=60)$.

\begin{tabular}{cccc}
\hline Age (months) & $\begin{array}{c}\text { Group A } \\
(\mathbf{n}=\mathbf{3 0})\end{array}$ & $\begin{array}{c}\text { Group B } \\
(\mathbf{n}=\mathbf{3 0})\end{array}$ & p value \\
\hline Mean \pm SD & $31.08 \pm 30.25$ & $34.70 \pm 42.73$ & $0.706^{*}$ \\
Range & $0.06-96$ & $0.13-144$ & \\
\hline
\end{tabular}

Table 2. Gender distribution of the study subjects between two groups $(\mathrm{N}=60)$.

\begin{tabular}{ccc}
\hline Sex & $\begin{array}{c}\text { Group A } \\
(\mathbf{n}=30)\end{array}$ & $\begin{array}{c}\text { Group B } \\
(\mathbf{n}=30)\end{array}$ \\
\hline Male & $16(53.3 \%)$ & $23(76.7 \%)$ \\
Female & $14(46.7 \%)$ & $7(23.3 \%)$ \\
\hline
\end{tabular}

most common disease was intussusceptions, that was 14 (46.7\%) in Group A and 16 (53.3\%) in Group B. Next common disease was intestinal obstruction due to bands and adhesion, which was $6(20.0 \%)$ and 5 (16.7\%) in Group A and Group B respectively. Perforated appendix was found in $4(13.3 \%)$ patients in Group A and $2(6.7 \%)$ patients in Group B. While perforation of small intestine due to blunt trauma was found in $1(3.3 \%)$ patient in Group A and $2(6.7 \%)$ patients in Group B (Table 3).

In this study mean wound closure time was $28.20 \pm 2.17$ minutes in Group A (Layered closure) and 18.80 \pm 1.67 minutes in Group B (Mass closure). It was observed that mean wound closure time was significantly $(\mathrm{p}<0.001)$ less in mass closure group as compared to layered closure group (Table 4).

Table 5 shows comparison of post-operative wound infection between two groups. Wound infection rate was relatively high [9 (30.0\%) patients] in Group A than Group B [3 (10.0\%) patients], but the difference was not statistically significant $(\mathrm{p}=0.053)$.

Among 60 study patients 12 patients had pus in their surgical wound due to wound infection during the post-operative periods. There were $9(30.0 \%)$ patients had pus in their surgical wound in Group A and that was $3(10.0 \%)$ patients in Group B, the difference was not statistically significant $(\mathrm{p}=0.053)$ (Table 6).

It was observed that pus was found in 12 patients among total 60 study patients of both groups. In culture media, pus from 2 patients showed growth of Escherichia coli in Group A and 1 patient in Group B. On the other hand, pus from 1 patient showed growth of Staphylococcus aureus in Group B. But pus from 8 patients showed no growth of offending organism in culture media (Table 7).

In this study it was found that the incidence of superficial wound dehiscence was comparatively less in mass closure group. Superficial wound dehiscence occurred among 8 (26.7\%) patients in Group A and 3 (10.0\%) patients in Group B, however the difference was not statistically significant $(\mathrm{p}=0.095)$ (Table 8).

Table 9 shows comparison of complete wound dehiscence between two groups. There was no complete wound dehiscence occurred in Group A patients, 
Table 3. Distribution of the study patients by disease in two groups $(\mathrm{N}=60)$.

\begin{tabular}{lcc}
\hline \multicolumn{1}{c}{ Disease } & $\begin{array}{c}\text { Group A } \\
(\mathbf{n}=30)\end{array}$ & $\begin{array}{c}\text { Group B } \\
(\mathbf{n}=30)\end{array}$ \\
\hline Intestinal obstruction due to & & \\
worm bolus (ascariasis) & $2(6.7 \%)$ & $0(0.0 \%)$ \\
diaphragmatic hernia & $0(0.0 \%)$ & $1(3.3 \%)$ \\
bands and adhesion & $6(20.0 \%)$ & $5(16.7 \%)$ \\
ladds band & $1(3.3 \%)$ & $0(0.0 \%)$ \\
mesenteric growth and bands & $0(0.0 \%)$ & $1(3.3 \%)$ \\
primary peritonitis & $1(3.3 \%)$ & $0(0.0 \%)$ \\
intestinal atresia & $1(3.3 \%)$ & $1(3.3 \%)$ \\
intussusception & $14(46.7 \%)$ & $16(53.3 \%)$ \\
twisted mesenteric cyst & $0(0.0 \%)$ & $1(3.3 \%)$ \\
volvulus of small intestine & $0(0.0 \%)$ & $1(3.3 \%)$ \\
Perforated appendix & $4(13.3 \%)$ & $2(6.7 \%)$ \\
Perforation of small intestine due to blunt trauma & $1(3.3 \%)$ & $2(6.7 \%)$ \\
\hline
\end{tabular}

Table 4. Comparison of wound closure time between two groups $(\mathrm{N}=60)$.

\begin{tabular}{cccc}
\hline Closure time (min) & $\begin{array}{c}\text { Group A } \\
(\mathrm{n}=30)\end{array}$ & $\begin{array}{l}\text { Group B } \\
(\mathrm{n}=30)\end{array}$ & p value \\
\hline Mean \pm SD & $28.20 \pm 2.17$ & $18.80 \pm 1.67$ & $<0.001^{*}$ \\
\hline
\end{tabular}

*Unpaired Student's " $\mathrm{t}$ " test was performed.

Table 5. Comparison of wound infection between two groups $(\mathrm{N}=60)$.

\begin{tabular}{cccc}
\hline Wound infection & $\begin{array}{c}\text { Group A } \\
(\mathbf{n}=\mathbf{3 0})\end{array}$ & $\begin{array}{c}\text { Group B } \\
(\mathbf{n}=\mathbf{3 0})\end{array}$ & p value \\
\hline Present & $9(30.0 \%)$ & $3(10.0 \%)$ & $0.053^{*}$ \\
Absent & $21(70.0 \%)$ & $27(90.0 \%)$ & \\
\hline
\end{tabular}

${ }^{*}$ Chi-Square test was performed.

Table 6. Presence of pus in surgical wound in two groups $(N=60)$.

\begin{tabular}{cccc}
\hline $\begin{array}{c}\text { Pus due to wound } \\
\text { infection }\end{array}$ & $\begin{array}{c}\text { Group A } \\
(\mathbf{n}=\mathbf{3 0})\end{array}$ & $\begin{array}{c}\text { Group B } \\
(\mathbf{n}=30)\end{array}$ & p value \\
\hline $\begin{array}{c}\text { Present } \\
\text { Absent }\end{array}$ & $9(30.0 \%)$ & $3(10.0 \%)$ & \\
\hline
\end{tabular}

${ }^{*}$ Chi-Square test was performed.

Table 7. Distribution of the patients according to pus culture.

\begin{tabular}{ccc}
\hline Growth of organism & Group A & Group B \\
\hline Escherichia coli & 2 & 1 \\
Staphylococcus aureus & 0 & 1 \\
No growth & 7 & 1 \\
Total & 9 & 3 \\
\hline
\end{tabular}

while that was in $1(3.3 \%)$ patient among 30 Group B patients, the difference was not statistically significant $(\mathrm{p}=0.313)$. 
Table 8. Comparison of superficial wound dehiscence between two groups $(\mathrm{N}=60)$.

\begin{tabular}{cccc}
\hline Superficial wound dehiscence & $\begin{array}{c}\text { Group A } \\
(\mathbf{n}=\mathbf{3 0})\end{array}$ & $\begin{array}{c}\text { Group B } \\
(\mathbf{n}=\mathbf{3 0})\end{array}$ & p value \\
\hline Present & $8(26.7 \%)$ & $3(10.0 \%)$ & \\
Absent & $22(73.3 \%)$ & $27(90.0 \%)$ & $0.095^{*}$ \\
\hline
\end{tabular}

${ }^{*}$ Chi-Square test was performed.

Table 9. Comparison of complete wound dehiscence between two groups $(\mathrm{N}=60)$.

\begin{tabular}{cccc}
\hline Complete wound dehiscence & $\begin{array}{c}\text { Group A } \\
(\mathbf{n}=\mathbf{3 0})\end{array}$ & $\begin{array}{c}\text { Group B } \\
(\mathbf{n}=\mathbf{3 0})\end{array}$ & p value \\
\hline Present & $0(0.0 \%)$ & $1(3.3 \%)$ & \\
Absent & $30(100.0 \%)$ & $29(96.7 \%)$ & $0.313^{\star}$ \\
\hline
\end{tabular}

${ }^{*}$ Chi-Square test was performed.

It was observed that post-operative incisional herniation was comparatively less in mass closure group. In Group A, 3 (10.0\%) patients developed incisional hernia and in Group B only 1 (3.3\%) patient developed incisional hernia; the difference was not statistically significant $(\mathrm{p}=0.031)$ (Table 10$)$.

\section{Discussion}

This prospective study was conducted in Department of Pediatric Surgery, Dhaka Medical College Hospital (DMCH), Dhaka, Bangladesh from July 2016 to June 2018. The aim of the study was to compare the outcomes between layered closure and mass closure postoperatively in transverse incision during emergency laparotomy in children. In the present study, age range in layered closure group was 0.06 - 96 months and in mass closure group that was $0.13-144$ months. Mean age in layered closure group and mass closure group was $31.08 \pm$ 30.25 months and $34.70 \pm 42.73$ months respectively. These findings were aligned with the findings of a previous study that showed the age range in both layered and mass closure group was 0.06 - 192 months [4]. But the age range of our study subjects was not similar with other studies [10] [16], where the study population were included 10 - 90 years of age [10] and 13 - 30 years of age [16].

In this study $53.3 \%$ study subjects were male and $46.7 \%$ were female in layered closure group, while $76.7 \%$ were male and $23.3 \%$ were female in mass closure group. In a previous study conducted by Kiely et al. (1985) on infants and children reported that, $63.64 \%$ and $61.42 \%$ were male in layered and mass closure group respectively [4]. In another study among 50 study patients age between 13 to 30 years reported that, $70 \%$ were male and $30 \%$ were female in mass closure group [16]. These findings were consistent with this current study.

Regarding the diseases of the study patients who underwent laparotomy, the most common disease of our study patients was intussusception which was 46.7\% in layered closure group and $53.3 \%$ in mass closure group. Next common disease was intestinal obstruction due to bands and adhesion which was $20.0 \%$ in layered closure group and $16.7 \%$ in mass closure group. In a previous study on 
Table 10. Comparison of incisional hernia between two groups $(\mathrm{N}=60)$.

\begin{tabular}{cccc}
\hline Incisional hernia & $\begin{array}{c}\text { Group A } \\
(\mathbf{n}=\mathbf{3 0})\end{array}$ & $\begin{array}{c}\text { Group B } \\
(\mathbf{n}=\mathbf{3 0})\end{array}$ & p value \\
\hline Present & $3(10.0 \%)$ & $1(3.3 \%)$ & \\
Absent & $27(90.0 \%)$ & $29(96.7 \%)$ & $0.301^{*}$ \\
\hline
\end{tabular}

${ }^{*}$ Chi-Square test was performed.

80 adult patients who underwent laparotomy reported that, 30\% was cholecystectomy and $27.5 \%$ was intestinal obstruction [10]. These findings were not similar to our findings because this current study was conducted among children needed emergency laparotomy.

In this study mean wound closure time was $28.20 \pm 2.17$ minutes in layered closure group and $18.80 \pm 1.67$ minutes in mass closure group. It was observed that mean wound closure time was significantly less in mass closure group as compared to layered closure group $(\mathrm{p}<0.001)$. Similar study was done by Deshmukh et al. (2018) [17] and Kendall et al. (1991) [18], they reported mean wound closure time in mass closure group was 16.2 minutes and 18 minutes respectively which were consistent with this current study.

In the present study post-operative wound infection rate was relatively high in Group A patients than Group B patients. We found, wound infection rate in mass closure group was $10 \%$ which was comparable with previous studies [17] [19]. On the other hand wound infection rate in layered closure group was $30.0 \%$ in this study, which was higher as compared to the previous studies [18] [20] [21]. It was observed that wound infection rate was higher in layered closure in comparison to mass closure; it may be due to more tissue handling and contamination during layered closure.

In this study cultures of pus (that obtained from wound infection) were done in 12 patients; among them pus from 3 patients showed growth of Escherichia coli, pus from 1 patient showed growth of Staphylococcus aureus and pus from 8 patients showed no growth of offending organism in culture media. In a previous study over a 14-month period among 676 infants and children who received an operative incision on the pediatric surgical service were followed-up for development of post-operative wound infection. Cultures were taken from wounds to identify the offending organisms and reported that Staphylococcus aureus, Escherichia coli and alpha hemolytic streptococcus were the most common wound pathogens [22]. In another study in adults, twenty bacterial strains were isolated from the 38 infected surgical incision sites, including Escherichia coli, Staphylococcus aureus, and Pseudomonas aeruginosa [23]. These findings were quite comparable with this current study.

In the present study superficial wound dehiscence was occurred in 8 (26.7\%) patients among layered closure group and that was in 3 (10.0\%) patients among mass closure group. As compared to mass closure group the superficial wound dehiscence was relatively higher in layered closure group although that was not statistically significant $(p=0.095)$. In a previous study among 206 study subjects 
documented that, the incidence of postoperative complications was $40.8 \%$, where wound dehiscence was only $0.5 \%$ [2]. Khan et al. (2015) noted superficial wound dehiscence was $8 \%$ in layered closure group and none in mass closure group [16]. Bucknall et al. (1982) demonstrated layered closure was associated with significantly higher superficial wound dehiscence rate compared with mass closure (3.8\% versus $0.76 \%$ ) [24]. Therefore our observation on superficial wound dehiscence was consistent with these previous studies.

In this study, no case of complete wound dehiscence was noted in layered closure group, while only one (3.3\%) case was in mass closure group. In a previous study it was showed that only two cases of burst abdomen with the layered closure technique among 80 study subjects [10]. In another prospective study among 1129 subjects over 5 years reported that, complete wound dehiscence was $3.8 \%$ in layered closure group and only $0.8 \%$ in mass closure group [24]. These findings were not accordant to our study. This dissimilarity may be due to age variation of the patients, several incisions were done during laparotomy, surgeon's heterogeneity and both emergency and routine operation was performed. It has been reported that abdominal wound dehiscence is a serious complication with high morbidity and mortality [8].

In this current study incisional hernia was developed among 3.3\% patients in mass closure group and $10.0 \%$ patients in layered closure group, that was comparable with previous studies [17] [20] [25]. But this finding was not similar to the study conducted by Kendall et al. (1991) as documented that incisional hernia was $3.5 \%$ in layered closure group and $6.5 \%$ in mass closure group respectively [18]. This may be due to good surgical technique in obtaining a high suture length to wound length ratio. The problem of incisional hernia is closely related to the suture technique. Ellis et al. (1977) [26] had reported a decrease in the incidence of incisional hernia with the mass closure technique which was consistent with this current study. While Bucknall et al. (1982) [24] reported no significant difference in the incidence of incisional hernia among different wound closure techniques. Several studies had shown that incisional hernia may occur many months after the operation and hence a suture technique that would provide enough tensile strength to the wound for a long time is essential [24] [25] [26] [27]. Late appearance of the incisional hernia was attributed to the fact that the aponeurosis which gives maximum strength to the abdominal wound heals much more slowly than the skin because of poor vascularity.

To summarize, this study demonstrated that the mass closure technique offers certain advantages over the layered closure technique with respect to the wound closure time, wound infection rate, incidence of superficial wound dehiscence and incidence of incisional hernia. However, there was no statistically significant difference between two groups in comparison of wound infection rate, incidence of wound dehiscence and incisional hernia. But as compared to layered closure mass closure technique was significantly less time consuming. Further study will be needed to find the ideal method of wound closure technique and efforts should be made to eliminate wound infection, decrease the incidence of wound 
dehiscence and incisional hernia.

\section{Conclusion}

In comparison with layered closure, mass closure technique was significantly less time consuming. Wound infection rate, incidence of superficial wound dehiscence, and incisional hernia were relatively less in mass closure group. This study concluded that mass closure technique is comparatively better than layered closure technique.

\section{Limitations of the Study}

It was a single center study with a relatively small sample size. Moreover, surgeon's heterogeneity and short period of follow up are also the mentionable limitations of this study.

\section{Recommendation}

Further large multicentre comparative studies with long term follow-up may reveal exact outcomes of both mass closure and layered closure techniques in transverse incision during emergency laparotomy in children.

\section{Conflicts of Interest}

The authors declare no conflicts of interest regarding the publication of this paper.

\section{References}

[1] Murtaza, B., Khan, N.A., Sharif, M.A., Malik, I.B. and Mahmood, A. (2010) Modified Midline Abdominal Wound Closure Technique in Complicated/High Risk Laparotomies. Journal of the College of Physicians and Surgeons Pakistan, 20, 37-41.

[2] Elkheir, I.S. and Idris, S.A. (2014) Evaluation of Abdominal Wall Closure Techniques in Emergency Laparotomies at a Peripheral Hospital. Scholars Journal of Applied Medical Sciences, 2, 1591-1595.

[3] Idris, S.A., Ali, A.Q., Shalayel, M.H., Idris, T.A. and Alegail, I.M. (2010) Design of Multicentre Study to Evaluate Frequency and Risk Factors for Wound Dehiscence/Burst Abdomen: A Study of 1683 Major Midline Laparotomies. Sudan Medical Monitor, 5, 185-191. https://doi.org/10.4314/sjms.v5i1.56036

[4] Kiely, E.M. and Spitz, L. (1985) Layered versus Mass Closure of Abdominal Wounds in Infants and Children. British Journal of Surgery, 72, 739-740. https://doi.org/10.1002/bjs.1800720923

[5] Dudley, H.A. (1970) Layered and Mass Closure of the Abdominal Wall, a Theoretical and Experimental Analysis. British Journal of Surgery, 57, 664-667. https://doi.org/10.1002/bjs.1800570908

[6] Fernandez, L.G. (2019) Abdominal Closure Technique. https://emedicine.medscape.com/article/1961789-technique

[7] Franz, M.G. (2010) Wound Healing. In: Doherty, G.M., Ed., Current Diagnosis \& Treatment: Surgery, 13th Edition, McGraw-Hill, New York, 6. 
[8] van Ramshorst, G.H., Salu, N.E., Bax, N.M., Hop, W.C., van Heurn, E., Aronson, D.C. and Lange, J.F. (2009) Risk Factors for Abdominal Wound Dehiscence in Children: A Case-Control Study. World Journal of Surgery, 33, 1509-1513. https://doi.org/10.1007/s00268-009-0058-7

[9] Dhamnaskar, S.S., Sawarkar, P.C., Vijayakumaran, P. and Mandal, S. (2016) Comparative Study of Efficacy of Modified Continuous Smead-Jones versus Interrupted Method of Midline Laparotomy Fascial Closure for Contaminated Cases. International Surgery Journal, 3, 1751-1756. https://doi.org/10.18203/2349-2902.isj20163541

[10] Singh, G. and Ahluwalia, R. (2012) A Comparison between Mass Closure and Layered Closure of Midline Abdominal Incisions. Medical Journal of Dr. DY Patil University, 5, 23-26. https://doi.org/10.4103/0975-2870.97505

[11] Ceydeli, A., Rucinski, J. and Wise, L. (2005) Finding the Best Abdominal Closure: An Evidence-Based Review of the Literature. Current Surgery, 62, 220-225. https://doi.org/10.1016/j.cursur.2004.08.014

[12] Pacifici, G.M. (2011) Pharmacokinetics of Cephalosporins in the Neonate: A Review. Clinics, 66, 1267-1274. https://doi.org/10.1590/S1807-59322011000700024

[13] Scher, K.S. (1997) Studies on the Duration of Antibiotic Administration for Surgical Prophylaxis. The American Surgeon, 63, 59-62.

[14] Wilson, A.P., Sturridge, M.F., Treasure, T. and Grüneberg, R.N. (1986) A Scoring Method (ASEPSIS) for Postoperative Wound Infections for Use in Clinical Trials of Antibiotic Prophylaxis. The Lancet, 327, 311-312. https://doi.org/10.1016/S0140-6736(86)90838-X

[15] Helton, W.S. and Al Fallouji, M.A.R. (1998) Adhesions, Post Graduate Surgery, the Candidates Guide. 2nd Edition, Betterworth-Heinemann, Oxford, 196-197.

[16] Khan, M.A., Akhtar, N. and Buzdar, M.U. (2015) Comparison between Mass Closure and Layered Closure in Major Abdominal Laparotomies. Pakistan Journal of Medical \& Health Sciences, 9, 962-965.

[17] Deshmukh, S.N. and Maske, A.N. (2018) Mass Closure versus Layered Closure of Midline Laparotomy Incisions: A Prospective Comparative Study. International Surgery Journal, 5, 584-587. https://doi.org/10.18203/2349-2902.isj20180357

[18] Kendall, S.W., Brennan, T.G. and Guillou, P.J. (1991) Suture Length to Wound Length Ratio and the Integrity of Midline and Lateral Paramedian Incisions. British Journal of Surgery, 78, 705-707. https://doi.org/10.1002/bjs.1800780623

[19] Israelsson, L.A. and Jonsson, T. (1994) Closure of Midline Laparotomy Incisions with Polydioxanone and Nylon: The Importance of Suture Technique. British Journal of Surgery, 81, 1606-1608. https://doi.org/10.1002/bjs.1800811114

[20] Khan, N.A., Almas, D., Shehzad, K., Chaudhry, A.K. and Mian, M.A. (2009) Comparison between Delayed-Absorbable Polydioxanone and Non-Absorbable (Prolene) Suture Material in Abdominal Wound Closure. Pakistan Armed Forces Medical Journal, 59, 64-69.

[21] Leaper, D.J., Pollock, A.V. and Evans, M. (1977) Abdominal Wound Closure: A Trial of Nylon, Polyglycolic Acid and Steel Sutures. British Journal of Surgery, 64, 603-606. https://doi.org/10.1002/bjs.1800640822

[22] Bhattacharyya, N. and Kosloske, A.M. (1990) Postoperative Wound Infection in Pediatric Surgical Patients: A Study of 676 Infants and Children. Journal of Pediatric Surgery, 25, 125-129. https://doi.org/10.1016/S0022-3468(05)80177-0

[23] Cheng, K., Li, J., Kong, Q., Wang, C., Ye, N. and Xia, G. (2015) Risk Factors for 
Surgical Site Infection in a Teaching Hospital: A Prospective Study of 1,138 Patients. Patient Preference and Adherence, 9, 1171-1177.

https://doi.org/10.2147/PPA.S86153

[24] Bucknall, T.E., Cox, P.J. and Ellis, H. (1982) Burst Abdomen and Incisional Hernia: A Prospective Study of 1129 Major Laparotomies. British Medical Journal (Clinical Research Ed.), 284, 931-933. https://doi.org/10.1136/bmj.284.6320.931

[25] Brolin, R.E. (1996) Prospective, Randomized Evaluation of Midline Fascial Closure in Gastric Bariatric Operations. The American Journal of Surgery, 172, 328-331. https://doi.org/10.1016/S0002-9610(96)00194-8

[26] Ellis, H. and Heddle, R. (1977) Does the Peritoneum Need to Be Closed at Laparotomy? British Journal of Surgery, 64, 733-736.

https://doi.org/10.1002/bjs.1800641013

[27] Goligher, J.C., Irvin, T.T., Johnston, D., De Dombal, F.T., Hill, G.L. and Horrocks, J.C. (1975) A Controlled Clinical Trial of Three Methods of Closure of Laparotomy Wounds. British Journal of Surgery, 62, 823-829.

https://doi.org/10.1002/bjs.1800621019 